\title{
Cystic dilation of the ventriculus terminalis
}

\author{
Masahiro Kawanishi, Hidekazu Tanaka, Kunio Yokoyama, Makoto Yamada \\ Department of Neurosurgery, Takeda General Hospital, Kyoto, Japan
}

ABSTRACT

The ventriculus terminalis (VT) is a virtual cavity of the conus medullaris that appears during embryonic life. We presented a case with the cystic dilation of the ventriculus terminalis (CDVT) in a symptomatic patient. A 66-year-old female suffered from disturbance while walking evolving for the past 2 years. An MR image revealed a cystic dilatation of ventriculus terminalis. The patient experienced marked improvement of lower extremity strength by a fenestration of cyst and cyst-subarachnoid shunt. Treatment for asymptomatic patients seems to be the best conducted conservatively, whereas patients with focal neurological deficits seem to be best handled surgically.

Key words: Cyst, dilatation, ventriculus terminalis

\section{Introduction}

Ventriculus terminalis (VT) is the name given to a congenital disorder that consists in the appearance of a small oval ependymal cystic cavity in the conus medullaris. It is formed during embryogenesis as a result of the differentiation between the canalization and regression of the spinal cord. ${ }^{[1]}$ Normally, such a cavity is identifiable only histologically in children and adults and can be visualized using common neuroradiological techniques only after dilation. Currently, the mechanisms of isolated dilation are not documented. The occurrence of its dilatation is very rare in adulthood. We describe a case of cystic dilatation of ventriculus terminalis (CDVT) in adult. The VT may present an abnormal dilation and we need to know its existence.

\section{Case Report}

A 66-year-old female was admitted to our hospital with hypoesthesia and dysesthesia of the lower limb,

\section{Address for correspondence:}

Dr. Masahiro Kawanishi, Department of Neurosurgery,

Takeda General Hospital, Kyoto, Japan.

E-mail: mkawanistakedahp@yahoo.co.jp

\begin{tabular}{|l|l|}
\hline \multicolumn{2}{|c|}{ Access this article online } \\
\hline Quick Response Code: & Website: \\
\hline & www.ruralneuropractice.com \\
\hline & \\
\hline
\end{tabular}

distal paresis, and disturbance while walking evolving for the past 2 years. Electromyogram confirmed radiculopathy. The patient's medical history has surgical intervention for cyst of conus medullaris 15 years ago, but the details are unknown. A magnetic resonance imaging (MRI) image revealed the presence of a cystic lesion located in the conus medullaris, with a well-defined outline, and which was not enhanced following contrast intravenous [Figure 1]. The patient underwent a T12-L1 laminectomy. Upon opening the dura, expand conus began herniating outward under pressure, which was relieved by a fenestration. Cerebrospinal fluid-colored fluid was drained to subarachnoid space [Figure 2a]. A histological examination revealed a simple cubic ependymal epithelium [Figure 2b]. Postoperatively, the patient experienced marked improvement in her lower extremity strength including lower limb control and gait recovery. Follow-up MRI scans 3 years later revealed complete regression of the dilation without evidence of relapse.

\section{Discussion}

The VT is an ependymal-lined cavity in the conus medullaris which is usually in continuity with the

This is an open access article distributed under the terms of the Creative Commons Attribution-NonCommercial-ShareAlike 3.0 License, which allows others to remix, tweak, and build upon the work non-commercially, as long as the author is credited and the new creations are licensed under the identical terms.

For reprints contact: reprints@medknow.com

How to cite this article: Kawanishi M, Tanaka $H$, Yokoyama K, Yamada M. Cystic dilation of the ventriculus terminalis. J Neurosci Rural Pract 2016;7:581-3. 
central canal of the spinal cord. The VT is formed during fetal development. In the normal development of the spinal cord, different stages are recognized as follows: Neurulation, canalization, and retrogressive differentiation [Figure 3]. During neurulation, which begins at 3 weeks of embryonic development, there is a flexion and closure of the neural plate to form the neural tube. The craniocephalic closure occurs within 23 days of gestation, ending at the anterior neuropore. The caudad closure is complete after approximately 26 days, ending at the posterior neuropore. At about $4-5$ weeks of gestation, the caudal end of the neural tube and the notochord combine to become an aggregate of undifferentiated cells, called the caudal cell mass. Small vacuoles develop within this mass, canalize, and form an ependymal-lined tube that usually fuses with most rostral central canals. This cavity is the VT or fifth ventricle. Finally, during retrogressive differentiation, a major portion of the distal cord involutes to become a glioependymal strand, the filum terminale. ${ }^{[2,3]}$ Present during fetal development, this space typically regresses after birth, although it has been detected in MRI scans in $2.6 \%$ of children under the age of 5 years imaged for unrelated symptoms. ${ }^{[1]}$ The CDVT represents a failure of regression of the VT; possible etiologies include failed fusion between the cranial and caudal neural tubes secondary to congenital disorders, trauma, and ischemia. ${ }^{[3]}$ An association between CDVT in children and the full spectrum of spinal dysraphism and tethered cords has been identified, but the exact causation has not been identified. Because descriptions of CDVT in adults have been limited to case reports and small series, true associations are harder to identify. ${ }^{[4]}$ The CDVT is a rare condition in adulthood. Only 45 cases have been reported to date, and 35 patients suffered from specific symptoms and were surgically treated. ${ }^{[5,6]}$ Treatment for patients without symptoms or with stable nonspecific low-back pain seems to be the best conducted conservatively whereas patients with focal neurological deficits seem to be best handled surgically. While some authors performed percutaneous aspiration of CDVT using real-time MRI and navigation with good early results, ${ }^{[7]}$ fenestration of the cyst and excision of a window with/without cystic-subarachnoid drainage is a safe and effective surgical technique to prevent its recurrence generally.

\section{Conclusion}

The VT is the ependymal cavity that lies in the conus medullaris. It may present an abnormal dilation and we need to know of its existence. Treatment for asymptomatic patients seems to be the best conducted
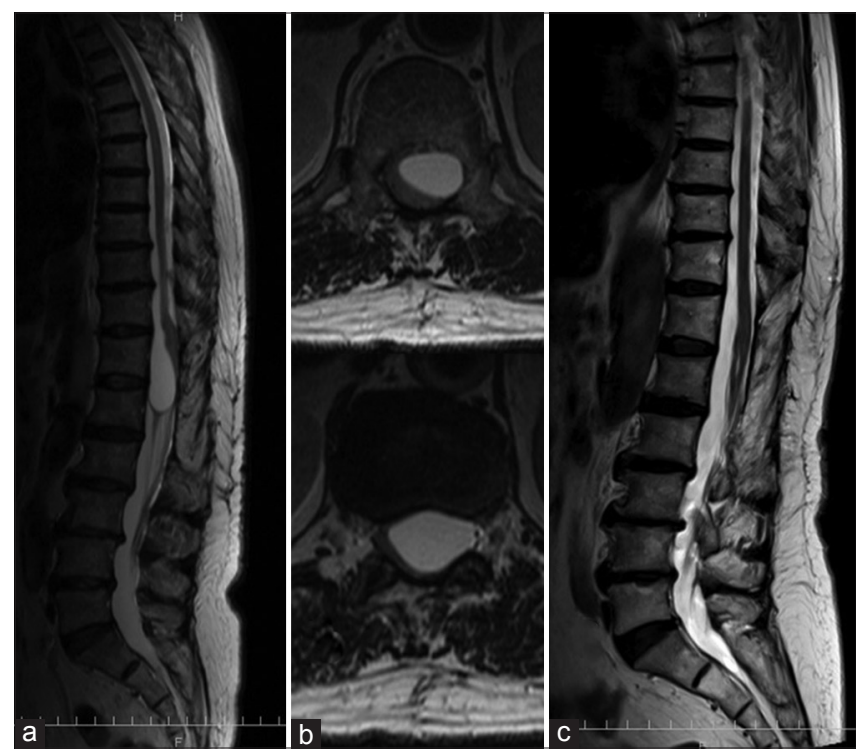

Figure 1: Magnetic resonance images. A preoperative T2-weighted image ( $a$ and $b$ ) shows the cystic dilatation of the conus medullaris, and postoperative T2-weighted images (c) obtained 3 years after surgical treatment shows regression of the dilatation without evidence of relapse

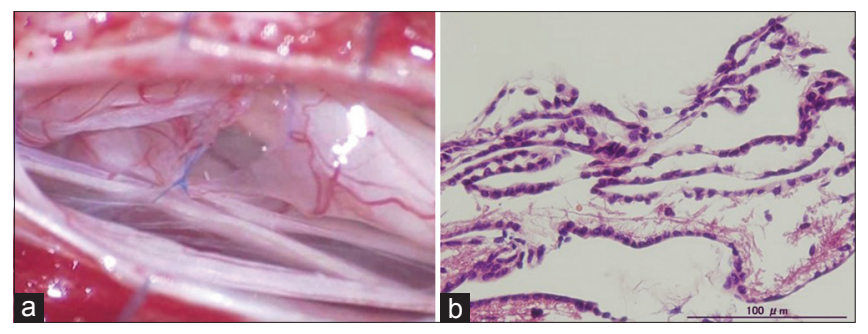

Figure 2: (a) Intraoperative image of the window of thin cyst wall with a suture (8.0). (b) Photomicrographs of histological samples obtained from wall of cyst, showing an ependymal-lined wall without any evidence of neoplastic proliferation $(\mathrm{H}$ and $\mathrm{E}, \times 400)$

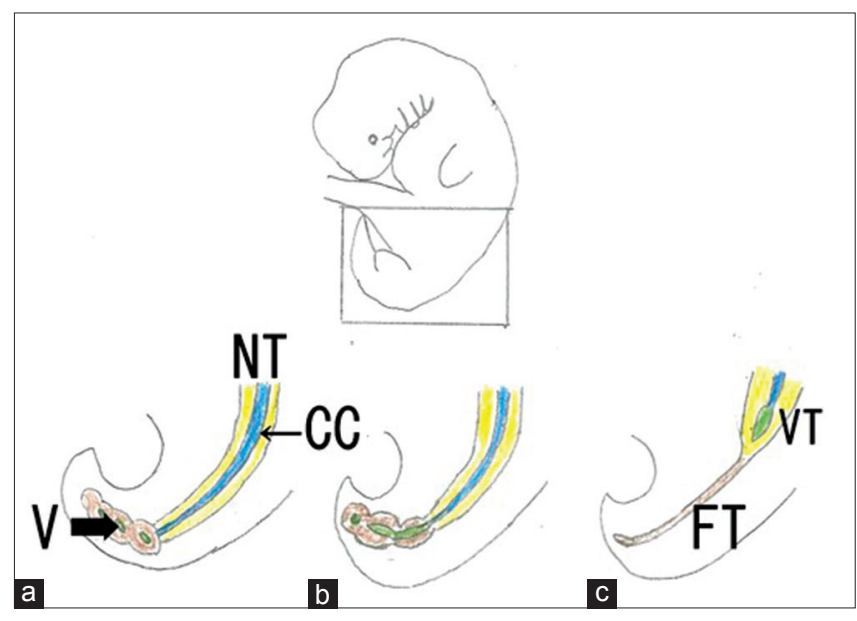

Figure 3: Embryologic development of the distal spinal cord. Central canal indicates central canal and neural tube (a) vacuolization. Small vacuoles (V green) form in the caudal cell mass (brown). (b) Canalization. The small vacuoles fuse to form a dilated ependymal-lined tube, which usually merges with the more rostral central canal. (c) Retrogressive differentiation. The dilated ependymal-lined canal becomes the ventriculus terminalis. FT indicates the filum terminale 
conservatively whereas patients with focal neurological deficits seem to be best handled surgically, including fenestration of the cyst and excision of a window with/ without cystic-subarachnoid drainage.

\section{Financial support and sponsorship}

Nil.

\section{Conflicts of interest}

There are no conflicts of interest.

\section{References}

1. Coleman LT, Zimmerman RA, Rorke LB. Ventriculus terminalis of the conus medullaris: MR findings in children. AJNR Am J Neuroradiol 1995;16:1421-6.
2. Ciappetta P, D’urso PI, Luzzi S, Ingravallo G, Cimmino A, Resta L. Cystic dilation of the ventriculus terminalis in adults. J Neurosurg Spine 2008;8:92-9.

3. Dullerud R, Server A, Berg-Johnsen J. MR imaging of ventriculus terminalis of the conus medullaris. A report of two operated patients and a review of the literature. Acta Radiol 2003;44:444-6.

4. Brisman JL, Li M, Hamilton D, Mayberg MR, Newell DW. Cystic dilation of the conus ventriculus terminalis presenting as an acute cauda equina syndrome relieved by decompression and cyst drainage: Case report. Neurosurgery 2006;58:E585.

5. Bellocchi S, Vidale S, Casiraghi P, Arnaboldi M, Taborelli A. Multilobed cystic dilation of the ventriculus terminalis (CDVT). BMJ Case Rep 2013;2013. pii: Bcr2013008654.

6. Ganau M, Talacchi A, Cecchi PC, Ghimenton C, Gerosa M, Faccioli F. Cystic dilation of the ventriculus terminalis. J Neurosurg Spine 2012;17:86-92.

7. Takahashi S, Saruhashi Y, Odate S, Matsusue Y, Morikawa S. Percutaneous aspiration of spinal terminal ventricle cysts using real-time magnetic resonance imaging and navigation. Spine (Phila Pa 1976) 2009;34:629-34. 